\title{
Scientometric analysis of endocrinology research from India
}

\author{
K. V. S. Hari Kumar*, K. Aravinda ${ }^{1}$, Sanjay Kalra ${ }^{2}$ \\ Department of Endocrinology, Command Hospital, ${ }^{1}$ Department of Oral Medicine and Radiology, CPGIDS and H, Lucknow, Uttar Pradesh, \\ ${ }^{2}$ Department of Endocrinology, BRIDE Hospital, Karnal, Haryana, India
}

\begin{abstract}
Background: Endocrinology research in India is rapidly growing without formal assessment. Our study analyzes the characteristics of all articles published by endocrinologists from India in PubMed indexed journals during the last decade. Materials and Methods: The data was obtained from PubMed database for the publications between 2001 and 2012 . The search terms used were "Endocrinology" in any field and "India" in the author affiliation field. The articles were analyzed for the type, gland and the institutional affiliation. We limit our analysis to clinical endocrinology and excluded basic and molecular endocrinology. Results: In total, 1160 articles were eligible for final analysis. Original articles (46\%), case reports $(26 \%)$ and reviews $(15 \%)$ constitute the majority while the remaining was shared between correspondence $(9 \%)$, images and editorials (3.5\% each). Pancreas and Diabetes (25\%) lead the subspecialty, followed by bone (19\%) and pituitary (16\%) disorders. Delhi (18\%), Chandigarh (13\%), Lucknow (10\%) are the top places contributing to the articles. Indian Journal of Endocrinology and Metabolism (24\%) and Journal of Association of Physicians of India (6\%) receive the maximum contributions. Conclusion: Our analysis suggest that the research from endocrinologists is growing in the last decade with equal contributions from all parts of the India.
\end{abstract}

Keywords: Endocrinology, India, research productivity, scientometric analysis

\section{INTRODUCTION}

India is witnessing a rapid change in disease burden with increasing prevalence of both communicable and non-communicable diseases. Endocrinology is a branch of medicine that deals with the glands, their hormones, metabolic functions of the body and related disorders. The change in life-style and demography of the population lead to rise in endocrine disorders such as diabetes and osteoporosis. ${ }^{[1]}$ Endocrinology as a subspecialty of internal medicine is relatively young

*Address for correspondence:

E-mail: hariendo@rediffmail.com

\begin{tabular}{|l|l|}
\hline \multicolumn{2}{|c|}{ Access this article online } \\
\hline Quick Response Code: & \\
\hline & Website: \\
\hline & www.jscires.org \\
& DOI: \\
\hline
\end{tabular}

in its existence and formal training is being imparted during the last three decades only from reputed postgraduate medical institutes. The awareness about thyroid and other endocrine conditions is increasing in all specialists leading to early diagnosis and treatment. The burden of non-communicable diseases has put more stress on the health care delivery systems including the requirement of specialist doctors. ${ }^{[2]}$ There are a number of academic institutes in the India imparting graduate and postgraduate medical education. These institutes are engaged in both patient care and research activities. The research productivity of Indian researchers is grossly inadequate in comparison to developed countries and even Asian countries like China. ${ }^{[3,4]}$ Population specific research activities are essential to unravel the mysteries of the disease pertaining to a geographical area.

Endocrinology as a subspecialty of medicine is relatively young in its existence when compared to cardiology and neurology. The research productivity of the endocrinology community in India is rapidly growing in recent years 
with increasing participation in national and international scientific meetings. There is a distinct increase in the contribution from endocrinology in the Journal of Association of Physicians of India (JAPI), the most popular medical journal in India. ${ }^{[5]}$ Indian Journal of Endocrinology and Metabolism (IJEM) is the flagship journal of the Endocrine Society of India and is growing at a rapid pace receiving submissions from India and other parts of the world. ${ }^{[6]}$ The journal is indexed in PubMed database for the last 2 years, which increases the visibility of the journal. The quality of the research determines the rate of acceptance by reputed journals. ${ }^{[7]}$ Academic institutes and corporate hospitals in India are actively involved in the endocrinology related research activities.

There is no formal assessment of the published literature about Endocrinology community from India. Hence, this work was carried out by the authors with the aim to analyze the nature and characteristics of endocrinology related articles published in PubMed indexed journals during the last decade. Our study focuses on the total research output, growth rate and distribution of publications by disease and glands, publication productivity of the institutions.

\section{MATERIALS AND METHODS}

This study is based on the research publications from India in the field of Endocrinology published in the PubMed indexed journals. The database pertaining to the last decade (2001-2012) was analyzed in this study. Initially, a search was undertaken of the PubMed citation database (www.ncbi.nlm.nih.gov/pubmed/) using the key words "Endocrinology" in any field and "India" in the author affiliation field. The search was conducted including all the areas of life sciences, health sciences etc., The flow diagram of the study is given in Figure 1. The articles pertaining to the basic endocrinology and molecular endocrinology have been excluded for this analysis. The available abstracts were studied by the authors and articles with data pertaining to animal studies and molecular, in vitro studies were excluded. We wanted to limit our study to the research in clinical endocrinology which is relevant to most clinicians and hence, excluded the data pertaining to basic and molecular endocrinology. The data were obtained independently by two authors (KVSHK, KA) and discrepancy if any was resolved in consultation with the third author (SK).

The identified abstracts were further analyzed individually and the data were derived from further analysis. The details about the journal, first author and last author, type of the article, branch of endocrinology and the institutional affiliation are recorded by the available data. The endocrinology related articles published in special issues and supplements also were included as they are part of the main PubMed database. The majority of the research work is published as original articles and space constraints may lead to the truncated version as a correspondence article. Publishing the interesting case reports, case series and interesting images also constitute the research activities. Editorials and review articles are generally written by invitation and are an important section of any journal.

For the purpose of this study, we divided all the articles into six (original articles, reviews, case reports, images, editorials and miscellaneous) types. The articles were divided into six broad groups based upon the gland being studied (pancreas and diabetes, thyroid, pituitary, adrenal and gonads, bone and miscellaneous). The classification is based on the list of important glands in the human body as described in our previous research article. ${ }^{[5]}$ We included adrenal and gonadal disorders under the same group as they have common features and presentation. The affiliation of the first author is taken as the place and department of study for the articles involving multiple authors from different institutes and departments. Traditionally, the first author is the person who is the main researcher and his mentor or guide is the last author. The last or corresponding author usually acts as the guarantor for the study and holds an important place in the list of authors. Hence, we included the details about the first and last author for each article. We included all the researchers from the Armed Forces as a single group due to their limited number.

\section{RESULTS}

Over the past 12 years, we identified 1160 citations eligible for final analysis of the research productivity as shown in Figure 1 . The majority of the articles originated from the Delhi followed closely by Chandigarh and Lucknow as shown in Figure 2. The research contribution is seen from all parts of the country and is rapidly catching up with the top places. Original articles (46\%), case reports $(26 \%)$ and review articles $(15 \%)$ constitute the majority, whereas the remaining 13\% is shared between editorials, images and letters to the editor [Figure 3]. The trend line of publications shows a gradual rise in the publications per year with a rapid rise during the last 2 years as shown in Figure 4.

Pancreas and Diabetes (25\%) lead the subspecialty articles followed closely by bone (19\%) and pituitary (16\%), 


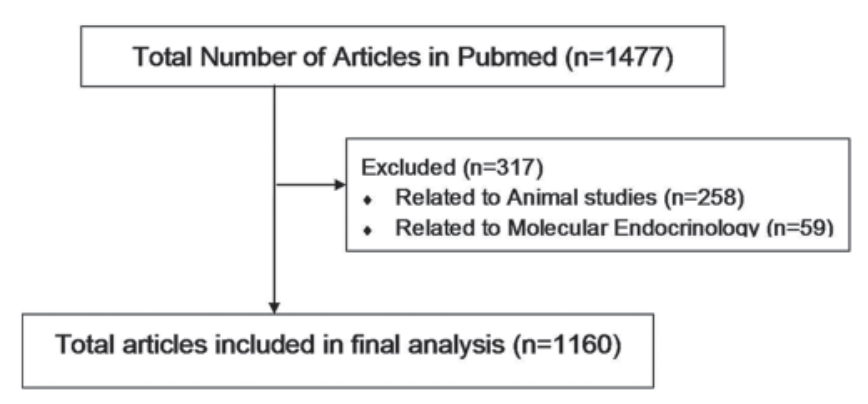

Figure 1: Flow diagram of the study

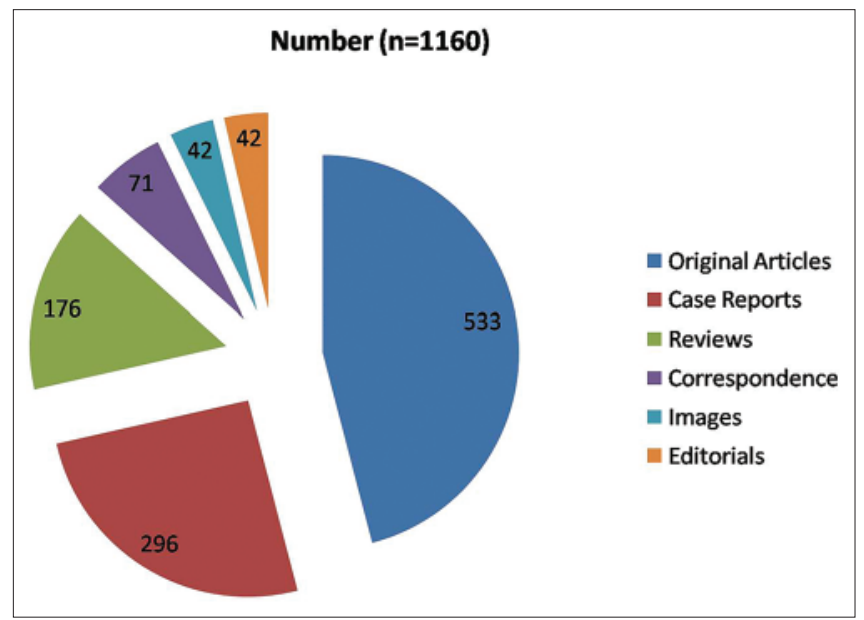

Figure 3: Types of the articles published

adrenal and gonads (15\%) and thyroid (12\%) disorders. The remaining articles (19\%) constitute the miscellaneous group, which includes articles pertaining to two or more endocrine glands and other articles. The contributions in the field of diabetes and thyroid disorders are declining and bone and pituitary disorders is increasing gradually over the last decade [Figure 5]. Table 1 gives the rankings of the most productive research institutes and the journals where the articles are published. Postgraduate Institute of medical education and Research (PGIMER), Chandigarh is ranked number one and is closely followed by All India Institute of Medical Sciences (AIIMS), New Delhi. IJEM (24\%) and JAPI $(6 \%)$ receive the maximum contributions from Indian authors. Dr. Anil Bhansali from PGIMER and Dr. Nalini Shah from Seth GS Medical College, Mumbai have the maximum number of publications as the first author and last author respectively. The contribution and impact of other authors is shown in Table 1. Endocrine Practice and the Clinical Endocrinology are the foreign journals with maximum contributions from Indian authors.

\section{DISCUSSION}

In this study, we analyzed the research activity of endocrinologists with reference to their total publication

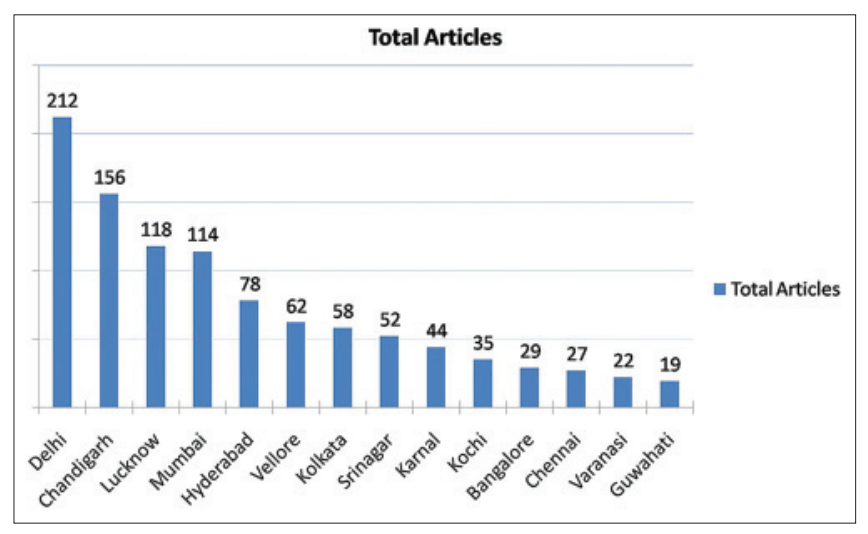

Figure 2: Research productivity of various cities

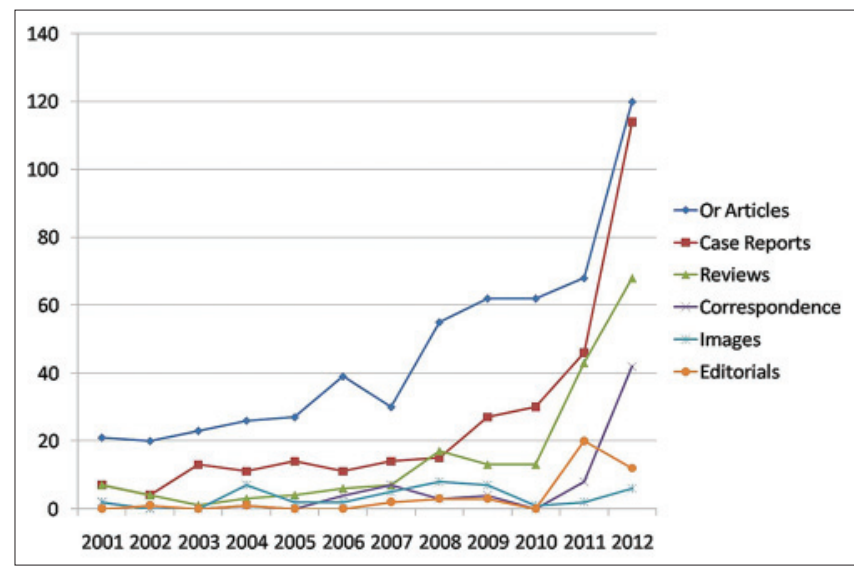

Figure 4: Publication trends of all articles from endocrinology from 2001 to 2012

output, growth rate and the quality of the output. Our study revealed lots of interesting observations which are mostly expected but some are unexpected. Most of the contributions in the field of endocrinology have come from the three cities (Delhi, Chandigarh and Lucknow). The other productive cities also have prestigious academic institutes imparting endocrinology training and are actively involved in teaching and research activities. ${ }^{[8]}$ Original articles take a major share of published articles, which is a good sign for the specialty. The diabetes and thyroid disorders offer enough number of patients to carry out original research work, but the research work pertaining to other endocrinology conditions is relatively lacking. This could be due to lack of affiliation at national level and difficulty in following up certain rare disorders. ${ }^{[0,10]}$ The share of review articles has increased dramatically with the indexing of IJEM in PubMed.

The publication trend from endocrinologists showed a gradual rise with a late surge in the year 2011 and 2012. This is due to the inclusion of IJEM in PubMed and also increase in the publication rate of the journal and 


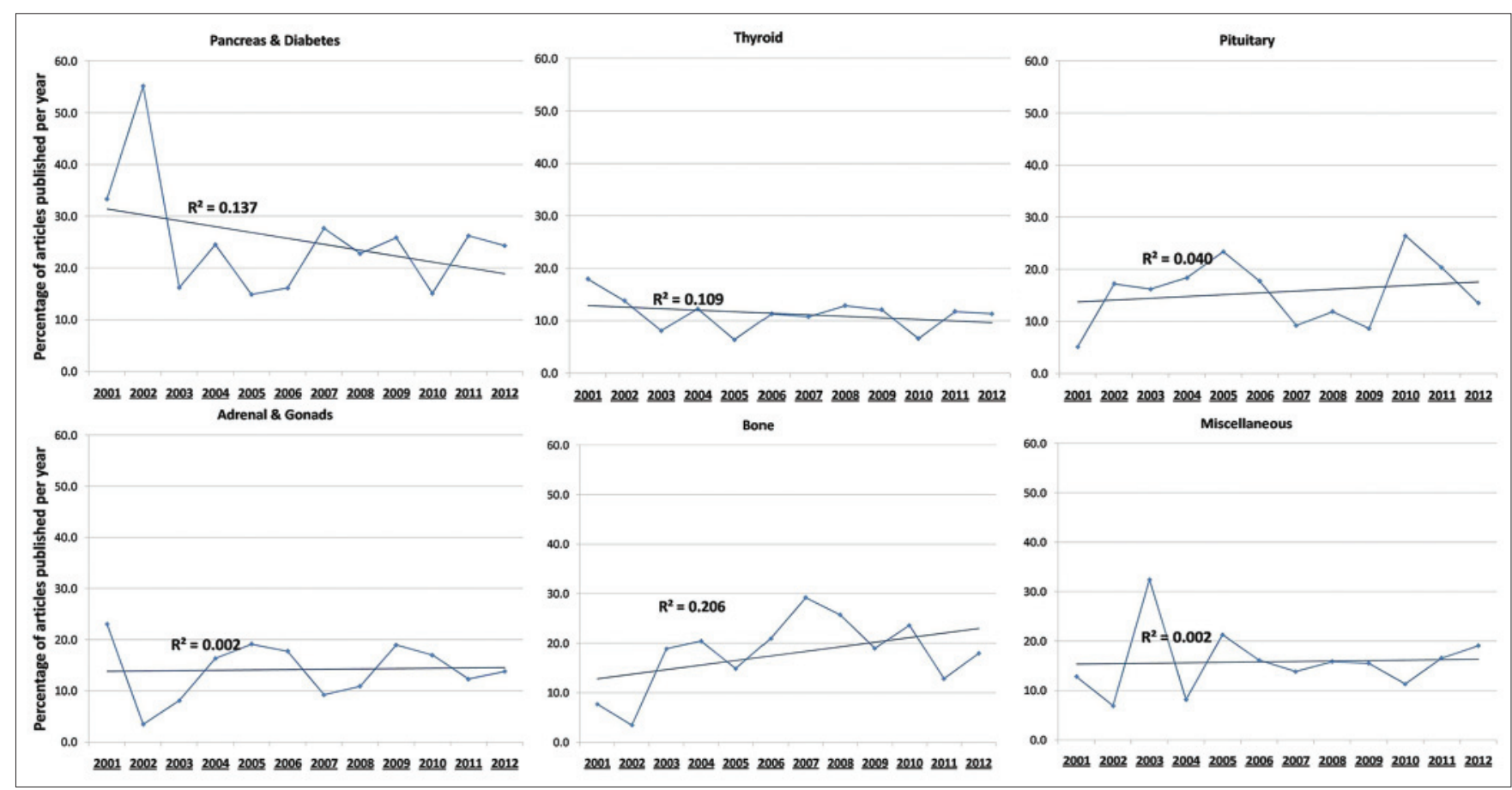

Figure 5: Trends of publishing as per the subspecialty in endocrinology

Table 1: The ranking of the authors, institutes and the journals in endocrinology based on the total number of publications

\begin{tabular}{|c|c|c|c|c|}
\hline \multicolumn{2}{|c|}{ Rank First author } & \multicolumn{2}{|c|}{ Last author Institute } & \multirow{2}{*}{$\begin{array}{l}\text { Journal } \\
\text { Indian J } \\
\text { Endocrinol } \\
\text { Metab }\end{array}$} \\
\hline 1. & Bhansali & Shah & $\begin{array}{l}\text { PGIMER, } \\
\text { Chandigarh }\end{array}$ & \\
\hline 2. & Kalra & Modi & AllMS, New Delhi & $\begin{array}{l}\text { J Assoc } \\
\text { Physicians India }\end{array}$ \\
\hline 3. & Kota & Chowdhury & Armed forces & $\begin{array}{l}\text { Endocrine } \\
\text { Practice }\end{array}$ \\
\hline 4. & Marwaha & Ammini & $\begin{array}{l}\text { Seth GS Medical } \\
\text { College, Mumbai }\end{array}$ & $\begin{array}{l}\text { J Pediatr } \\
\text { Endocrinol } \\
\text { Metab }\end{array}$ \\
\hline 5. & Hari Kumar & Bhansali & CMC, Vellore & Ind J Med Res \\
\hline 6. & Bhadada & Thomas & $\begin{array}{l}\text { Medwin hospitals, } \\
\text { Hyderabad }\end{array}$ & $\begin{array}{l}\text { Indian } \\
\text { Pediatrics }\end{array}$ \\
\hline 7. & Unnikrishnan & Zargar & SKIMS, Srinagar & $\begin{array}{l}\text { Indian Journal } \\
\text { of Pediatrics }\end{array}$ \\
\hline 8. & Zargar & Seshadri & SGPGI, Lucknow & $\begin{array}{l}\text { BMJ Case } \\
\text { Reports }\end{array}$ \\
\hline 9. & Goswami & Bhadada & CDRI, Lucknow & $\begin{array}{l}\text { Diab Res Clin } \\
\text { Pract }\end{array}$ \\
\hline 10. & Dutta & Dash & $\begin{array}{l}\text { BRIDE Hospital, } \\
\text { Karnal }\end{array}$ & $\begin{array}{l}\text { Clinical } \\
\text { Endocrinology }\end{array}$ \\
\hline
\end{tabular}

its supplements. This is heartening as the researchers from India have an opportunity to share their research work with a global audience. Figure 5 shows interesting trend lines of research productivity pertaining to the individual glands. The graph shows that the maximum research productivity involves disorders of the pancreas and diabetes. The trendline demonstrates that apart from diabetes, the endocrinologists are doing more research in bone and pituitary disorders. The diseases of these organs are in specialized domain and require the expertise of the endocrinologist in their approach and management. ${ }^{[1]}$ Hence, the research activity is also increasing in these subspecialties of the endocrinology. The declining contributions from the endocrinology community in diabetes and thyroid disorders could be due to physicians carrying research activity in these disorders without involving the endocrinologists. ${ }^{[12]}$ Overall, the trends reveal that there is increasing research pertaining to all the endocrine disorders apart from diabetes.

The research contribution in endocrinology is seen from all parts of the country. PGIMER is the top most productive research institute followed closely by AIIMS. This is self-explanatory as they have the oldest Departments of Endocrinology in India and are responsible for shaping up the specialty of endocrinology in India. ${ }^{[13]}$ The heartening fact is that the research contributions are seen increasingly from across the length and breadth of the country, even from small places like Srinagar, Karnal and Guwahati. There are two private hospitals located in the top ten rankings and the rest are all training institutes with undergraduate and postgraduate teaching. There is growing contribution from both government and private hospitals involved in the management of endocrinology patients.

The majority of the research articles is published in IJEM and the Indian journals with limited number of 
publications in the leading journals of the specialty. ${ }^{[14]}$ The growth of pediatric endocrinology as a separate branch is evident by the presence of many publications in the pediatric journals as seen in Table 1. The total number of the articles published in Journal of Clinical Endocrinology and Metabolism (JCEM) and European Journal of Endocrinology (EJE) is $<30$ during the last decade (data not shown). The research productivity from India pertains mostly to clinical endocrinology with limited molecular and genetic analysis. Hence, the articles are more likely to get accepted in journals with focus on clinical aspects like Endocrine Practice (Official journal of the American Association of Clinical Endocrinologists) and the Clinical Endocrinology (Official journal of the Society for Endocrinology, UK). The bridge between basic endocrinology and clinical endocrinology is wide in our country and efforts are required to close this gap from the leaders in the field of endocrinology.

Our analysis, though exhaustive has certain limitations. First, we searched only PubMed indexed journals and there is likely that the research is published in a biomedical journal not included in the Medline database. Second, our exclusive search term of "Endocrinology" may exclude a few citations from the display panel. Third, few citations would have been missed if the term "India" was not mentioned in the author affiliation.

\section{CONCLUSION}

Our analysis showed that the research productivity of endocrinology community is increasing during the last decade in PubMed indexed journals. The researchers are located in all parts of India and there is equal contribution from government and private hospitals. Research activity should be part of curriculum for medical undergraduates to develop interest in the subject and government funding should be available easily for major research projects. IJEM is helping the Indian researchers to showcase their research talent to a global audience.

\section{ACKNOWLEDGMENTS}

The authors sincerely acknowledge the help rendered by K. V. Pranav in the conduct of this study.

\section{REFERENCES}

1. Anjana RM, Pradeepa R, Deepa M, Datta M, Sudha V, Unnikrishnan R, et al. Prevalence of diabetes and prediabetes (impaired fasting glucose and/or impaired glucose tolerance) in urban and rural India: Phase I results of the Indian Council of Medical Research-INdia DIABetes (ICMR-INDIAB) study. Diabetologia 2011;54:3022-7.

2. Ananthakrishnan N, Arora NK, Chandy G, Gitanjali B, Sood R, Supe $A$, et al. Is there need for a transformational change to overcome the current problems with postgraduate medical education in India? Natl Med J India 2012;25:101-8.

3. Gupta BM, Bala A. A scientometric analysis of Indian research output in medicine during 1999-2008. J Nat Sci Biol Med 2011;2:87-100.

4. Dandona L, Raban MZ, Guggilla RK, Bhatnagar A, Dandona R. Trends of public health research output from India during 2001-2008. BMC Med 2009;7:59.

5. Kumar KV, Aravinda K. Trends in endocrinology related research articles in a medical journal from India. Indian J Endocrinol Metab 2012;16:931-4.

6. Kalra S, Baruah M, Unnikrishnan AG, Sahay R. Publication trends in the Indian Journal of Endocrinology and Metabolism. Indian J Endocrinol Metab 2011;15:27-30.

7. Satyanarayana K. Impact factor and other indices to assess science, scientists and scientific journals. Indian J Physio Pharmacol 2010;54:197-212.

8. Deo MG. Need for research oriented medical education in India. Indian J Med Res 2009;130:105-7.

9. Balakrishnan V, Unnikrishnan AG, Thomas V, Choudhuri G, Veeraraju $\mathrm{P}$, Singh SP, et al. Chronic pancreatitis. A prospective nationwide study of 1,086 subjects from India. JOP 2008;9:593-600.

10. Kothari R. Medical education in India: A need to think differently. Natl Med J India 2012;25:99-100.

11. Garg MK, Kharb S, Brar KS, Gundgurthi A, Mittal R. Medical management of pheochromocytoma: Role of the endocrinologist. Indian J Endocrinol Metab 2011;15 Suppl 4:S329-36.

12. Deepa M, Pradeepa R, Rema M, Mohan A, Deepa R, Shanthirani S, et al. The Chennai Urban Rural Epidemiology Study (CURES) - Study design and methodology (urban component) (CURES-I). J Assoc Physicians India 2003;51:863-70.

13. Kalra S, Unnikrishnan AG, Joshi S. Academic endocrinology in India: Forty, fifteen or both? Indian J Endocrinol Metab 2011;15:237-8.

14. Kasoju N, Bora U. Improving the standards of scientific publishing in India. Indian J Med Res 2010;132:523-4.

How to cite this article: Kumar KH, Aravinda K, Kalra S. Scientometric analysis of endocrinology research from India. J Sci Res 2013;2:132-6.

Source of Support: Nil, Conflict of Interest: None declared 